\title{
Autologous hematopoietic stem cell transplant for autoimmune diseases: evolution, evidence of efficacy, and real-world economics
}

\author{
Massey, Jennifer C. 1,2,3, Moore, John J. ${ }^{2,3,4}$, Milliken, Samuel T. ${ }^{4}$, Ma, David D. F. ${ }^{2,3,4,5}$ \\ ${ }^{1}$ Department of Neurology, St Vincent's Hospital Sydney, Australia, ${ }^{2}$ Blood, Stem Cell and Cancer Research Program, St \\ Vincent's Centre for Applied Medical Research, Sydney, Australia, ${ }^{3}$ St Vincent's Clinical School, Faculty of Medicine, \\ University of NSW, Sydney, Australia, ${ }^{4}$ Department of Haematology and Bone Marrow Transplant, St Vincent's Hospi- \\ tal Sydney, Australia, ${ }^{5}$ Corresponding author
}

\section{Abstract}

Despite an increase in the development of biological therapies for autoimmune disease (AID), a proportion of patients remain treatment refractory, resulting in long term morbidity and increased rates of mortality. Furthermore, maintenance biologic therapies are associated with treatment-related side effects, significant financial cost, and restricted access, which is of particular relevance in the developing world. Although it carries a significant 'front loaded' cost both financially and regarding adverse events, autologous hematopoietic stem cell transplantation (AHSCT) represents a potential single therapeutic intervention, which in the appropriate patient, condition, and transplant center, may offer sustained disease remission resulting in improved overall survival, disease relapse-free survival, improved quality of life, and decreased financial burden.

Emerging Phase II and III trial and registry data, to which our center has been a significant contributor over the past two decades, are providing invaluable evidence as to which AIDs are most likely to receive a sustained benefit from AHSCT and which conditioning regimens are preferable. Similar to trends for the treatment of malignant disease, AHSCT for AID may find a place in both developed and developing countries as nations become more familiar with the transplantation process. If this occurs, benchmarking by key regulatory bodies, collaboration between medical specialties, and the development of experienced 'centers of excellence' will be key to enhance safety and benefit to patients and society at large.

Key words: Autoimmune disease, Autologous transplant

Submitted September 14, 2018; Accepted October 23, 2018; Published online April 1, 2019; Issued online May 10, 2019

Correspondence: David Ma, Dept of Haematology and MB Transplant, St Vincent's Hospital Sydney. Programme Head, St Vincent's Applied Medical Research Sydney. Professor Conjoint, Faculty of Medicine, University of NSW, 390 Victoria Street, Darlinghurst, NSW 2010 Australia, E-mail: a.lafferty@ amr.org.au

\section{Introduction}

Autoimmune diseases (AID) are a heterogeneous group of inflammatory conditions affecting 9-20\% of the population ${ }^{1}$. An increasing incidence of AID has been reported within the developed world over the last half century ${ }^{2}$, a trend likely to be replicated in the developing world with rising industrialization and urbanization. A proportion of these disorders demonstrate a predilection for early adulthood, resulting in chronic diseases that cumulatively impose a growing disease burden on the community. Certain 'classical' autoimmune disorders are defined by well-characterized auto-antigens, while the cause of other AIDs remains poorly understood. Key factors postulated to influence the development of AIDs include over-activation of autoreactive $\mathrm{T}$ and $\mathrm{B}$ cells and reduced immunoregulatory capacity of regulatory lymphocytes in patients with a predisposing genetic background ${ }^{3}$. Treatments that recalibrate this dysregulation could induce a period of clinical remission, if not long-term cure.

Despite a rising prevalence, most autoimmune disorders remain incurable, with patients requiring chronic immunosuppressive therapies and/or supportive treatment, which confer significant short- and long-term side 
effects, costs, and often fail to mimic normal biology leading to a reduced quality of life and survival. Autologous hematopoietic stem cell transplant (AHSCT) has been tested as a treatment option for patients with severe AID. The principle behind AHSCT in AID is of nonselective ablation of autoreactive lymphocytes through immunosuppression with high dose (HD) chemotherapy, supported by hematopoietic stem cell 'rescue' to induce bone marrow recovery. It is hypothesized that HD chemotherapy eradicates the expanded pathogenic lymphoid clones, followed by reconstitution of a 'normal' immune system $^{4}$. Significant recent improvements in the transplant procedure mean that, relative to the morbidity and mortality associated with certain AIDs (severe subgroups of systemic sclerosis, SLE, Crohn disease, and multiple sclerosis) the risk of AHSCT is increasingly accepted by both patients and physicians. Published trial evidence shows that appropriate patient selection is key in optimizing transplant outcomes. Patients should be referred following the failure of standard treatments, but preferably still be in the early, active phase where the disease is susceptible to immunoablation and reconstitution before irreversible end organ damage occurs. It is increasingly clear that AHSCT can induce long term disease stabilization in the absence of further disease-modifying therapy (DMT) in many AIDs, with real-world data sets such as the European Group for Blood and Marrow Transplantation (EBMT) and the Center for International Blood and Marrow Research (CIBMR) enlightening patient selection choices and transplantation protocols to further optimize outcomes.

Observational studies followed by phase I and II clinical trials, and more recently randomized phase III studies have clarified the role of AHSCT in various $\mathrm{AIDs}^{4-6}$, to which our center has been a longstanding contributor. Over the last two decades, we have conducted and participated in several clinical trials to evaluate the role of AHSCT in various autoimmune diseases in over a hundred patients. Additionally, we have been privileged to have a long-standing alliance with the EBMT and were founding collaborators with the European League Against Rheumatism (EULAR) in developing the first Autoimmune Disease Working Party (ADWP) through the EBMT. This review aims to summarize the evolution of AHSCT as a treatment modality for AID and review the current evidence by disease type. Furthermore, we postulate on the global implementation of AHSCT for AID in the future based on our experience in this field to date.

\section{History of AHSCT in autoimmune disease}

AHSCT has been utilized as a therapeutic intervention in aggressive autoimmune disease over the past two decades. The first successful bone marrow transplanta- tion (BMT) was performed in 1956. Subsequently, in a review in Science, 1971, Congdon accurately predicted the role of BMT to extend beyond the field of cancer ${ }^{7}$. Therapeutic trials of total body irradiation (TBI) or cyclophosphamide and busulfan ${ }^{8}$ with allogeneic BMT in rats with experimental encephalomyelitis (EAE - an animal model for multiple sclerosis) showed that transplantation can induce disease remission, prevent relapses and enhance recovery from paresis. Furthermore, anecdotal reports of co-incidental improvement of auto-immune disease symptoms in patients undergoing transplantation for cancer ${ }^{9}$ provided a basis for further exploration of HSCT for AID. The concept of immunoablation with autologous stem cell rescue in severe AID was then established using animal models of disease, and felt to be more acceptable to both physicians and patients in the context of AID due to feasibility and safety concerns about allogeneic transplantation. Pivotal work in rodent models of AID including inflammatory arthritis and EAE, demonstrated that autologous BMT could be successful in inducing variable periods of disease remission ${ }^{10,11}$ and thus paved the way for translational human trials ${ }^{12,13}$. It was recognized early that AHSCT is most effective in the active inflammatory phase of the AID and ineffective in the late chronic stage when tissue and organ damage is irreversible. AHSCT has now been trialed in a host of inflammatory conditions including connective tissue disorders (CTD), inflammatory arthritis, neurological diseases (most notably multiple sclerosis), inflammatory bowel disease (IBD), and type 1 diabetes mellitus. According to the autoimmune disease working party of the EBMT, 2306 patients have undergone AHSCT for AID since 1995, with multiple sclerosis making up the largest indication for treatment to date ${ }^{14}$.

\section{Fundamentals of HSCT-The procedure}

The AHSCT procedure can be considered in five key parts (Figure 1):

$\rightarrow$ Mobilization of hematopoietic stem cells (HSCs) from the bone marrow to peripheral blood

$\rightarrow$ HSC apheresis

$\rightarrow$ Conditioning chemotherapy

$\rightarrow$ Infusion of autologous HSC's

$\rightarrow$ Supportive care until the recovery of a functioning hematopoietic system

The mobilization of peripheral blood stem cells is typically induced with a hematopoietic stimulating agent such as granulocyte colony stimulating factor and/or cyclophosphamide. Cyclophosphamide is used to increase HSC yield, counter the potential worsening of AID that has been associated with sole G-CSF use ${ }^{15}$, and theoretically reduce the risk of autoreactive cells entering the 


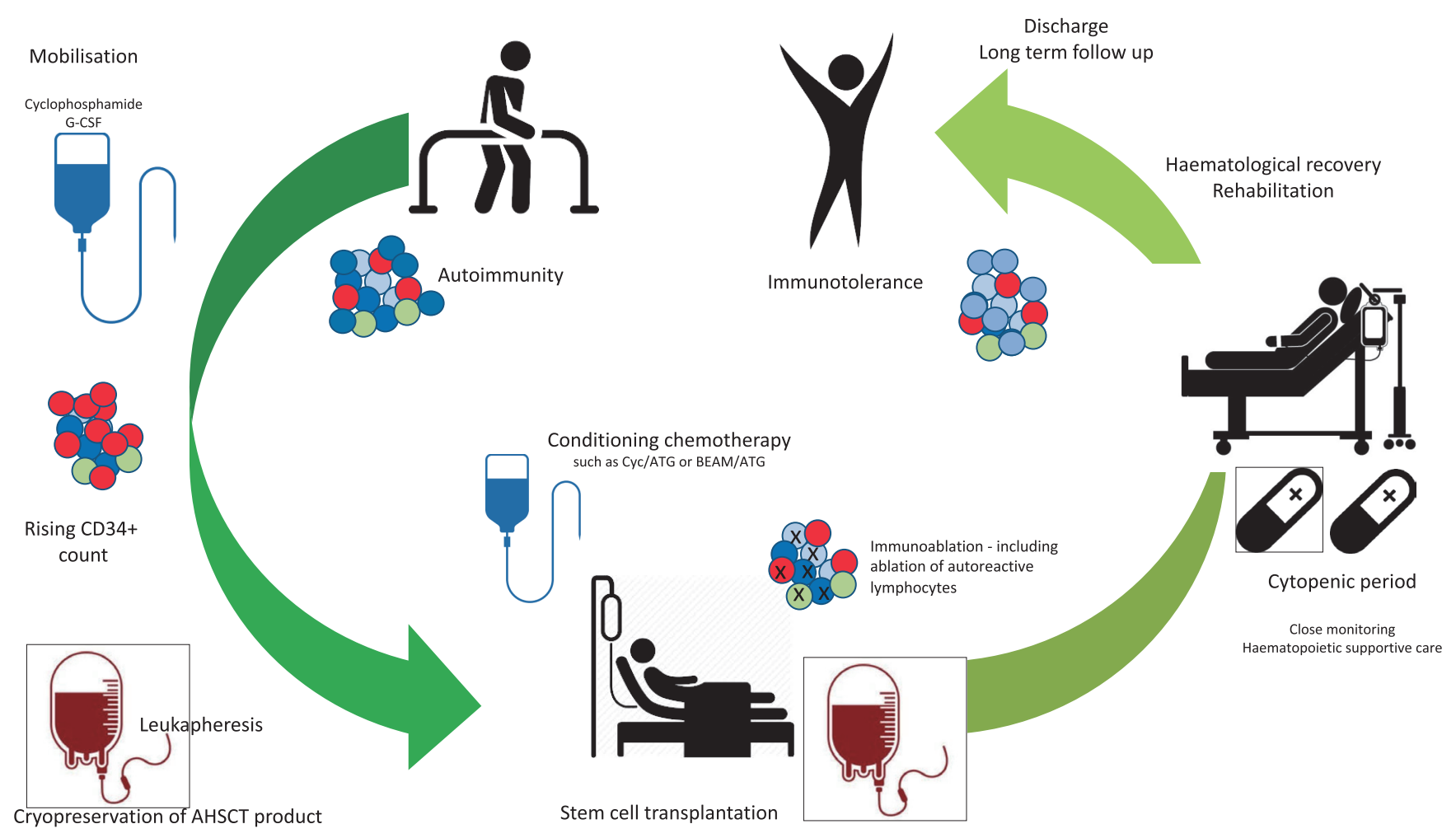

Figure 1. The AHSCT procedure

apheresis product. Ex-vivo CD34 + HSC selection of the leukapheresis product has been trialed in clinical practice, with the belief that purification of the graft product can decrease the 'load' of autoreactive $\mathrm{T}$ cells re-entering the patient ${ }^{16}$. Contrary to this, the only study to prospectively address the question, a randomized controlled trial (RCT) conducted by our center in rheumatoid arthritis patients undergoing AHSCT, did not show any benefit from HSC selection ${ }^{17}$. In centers where CD34 + selection is not performed, it is common for patients to receive anti-thymocyte globulin (ATG) on the days following graft infusion.

Conditioning regimens can be grouped by level of intensity or as lymphoablative or myeloablative. The advocated degree of immunoablation differs between diseases and has typically been built out of phase 1 and 2 trials rather than through classical 'dose finding' studies. As an example, in the context of multiple sclerosis, observational data suggest a longer relapse-free period and improved MRI outcomes have been seen in myeloablative regimens ${ }^{18,19}$ that employ either cyclophosphamide/total body irradiation (TBI), busulfan/cyclophosphamide, or BEAM (BCNU, etoposide, cytarabine, and melphalan), but at the cost of higher toxicity. Lower intensity lymphoablative regimens have typically used cyclophosphamide + ATG, or alemtuzumab. As such, BEAM is now the most common conditioning regimen used for MS worldwide

Conditioning regimens, level of evidence for efficacy, and key clinical trial results by disease are outlined in Table 1. While less intensive regimens may not necessitate HSC infusion, the role of hematopoietic stem cells is believed to serve two primary purposes: 1) to reduce morbidity and mortality by shortening the duration of pancytopenia and 2) to promote a 'broader' immune reconstitution beyond any residual cells surviving conditioning. It remains debated as to whether the stem cell infusion should be considered merely bone marrow rescue, or whether an additional therapeutic benefit is conferred ${ }^{20}$.

\section{Clinical Evidence for AHSCT in various AIDs}

\section{Systemic sclerosis}

Systemic sclerosis $(\mathrm{SSc})$ is the most common CTD for which AHSCT is performed. SSc is a multi-system AID in which abnormal connective tissue deposition results in skin and visceral fibrosis. In patients with severe diffuse cutaneous disease, the five-year mortality rate is estimated to be around $30 \%{ }^{21}$. Given this poor prognosis, and the lack of an effective treatment, pilot studies through the mid-2000's paved the ground for three randomized trials (RCT) of AHSCT vs medical therapy in SSc - the ASSIST, ASTIS, and SCOT trial-all of which have demonstrated superiority of AHSCT over intravenous cyclophosphamide (best conventional treatment $)^{22-24}$. 
Table 1. Summary of evidence and current recommendations for AHSCT by autoimmune disease

\begin{tabular}{|c|c|c|c|c|}
\hline $\begin{array}{l}\text { Autoimmune } \\
\text { Disease }\end{array}$ & $\begin{array}{c}\text { Highest level evidence for } \\
\text { AHSCT }\end{array}$ & Recent publications & Conditioning regimens & Current recommendations \\
\hline $\begin{array}{l}\text { System ic } \\
\text { Sclerosis }\end{array}$ & $\begin{array}{l}3 \text { randomised controlled trials } \\
\text { of AHSCT vs. IV cyclophos- } \\
\text { phamide. ASSIST }{ }^{22} \text {-single } \\
\text { centre phase II trial. ASTIS }{ }^{24} \text { - } \\
\text { phase III RCT. SCOT }{ }^{23} \text { trial- } \\
\text { phase III RCT. }\end{array}$ & $\begin{array}{l}\text { SCOT trial (2018) Myeloabla- } \\
\text { tive CD34+ selected AHSCT } \\
\text { vs. yearly cyclophosphamide. } \\
\text { At } 72 \text { months-OS } 86 \% \text { v } 51 \% \\
\text { and EFS } 74 \% \text { v } 47 \% \text {. }\end{array}$ & $\begin{array}{l}\text { ASSIST/ASTIS: } 200 \text { mg/kg } \\
\text { IV Cyc+6.5 mg/kg ( } 7.5 \\
\text { mg/kg ASTIS) IV ATG (rab- } \\
\text { bit). SCOT: Fractionated } \\
\text { TBI ( } 800 \text { cGy), IV Cyc } 120 \\
\mathrm{mg} / \mathrm{kg}+90 \mathrm{mg} / \mathrm{kg} \text { IV ATG } \\
\text { (rabbit). }\end{array}$ & $\begin{array}{l}\text { A HSC T is indicated in } \\
\text { patients with severe diffuse } \\
\text { cutaneous SSc at early } \\
\text { inflammatory stage and major } \\
\text { organ involvement with docu- } \\
\text { mented disease progression. }\end{array}$ \\
\hline SLE & $\begin{array}{l}\text { Retrospective survey of regis- } \\
\text { try data. Single centre pro- } \\
\text { spective studies. }\end{array}$ & $\begin{array}{l}\text { AHSCT for SLE-EBMT data } \\
(2013) .28 \text { patients in } 8 \text { cen- } \\
\text { tres. } 5 \text { yr OS } 81 \% \text {, disease free } \\
\text { survival } 29+/-9 \% \text {, relapse } \\
\text { rates } 56 \% \text {. }\end{array}$ & $\begin{array}{l}10 / 28 \text { IV Cyc or Melphalan } \\
\text { (low intensity) or } 18 / 28 \\
\text { Cyc+ATG or fludarabine, } \\
\text { alemtuzumab and melpha- } \\
\text { lan (intermediate intensity). }\end{array}$ & $\begin{array}{l}\text { An option for certain sub- } \\
\text { groups of patients where sus- } \\
\text { tained or relapsed activity } \\
\text { occurs after } 6 \text { months of } \\
\text { standard therapy, and theo- } \\
\text { retically early in disease. }\end{array}$ \\
\hline Arthritis & $\begin{array}{l}\text { Retrospective survey of regis- } \\
\text { try data from single centre } \\
\text { prospective studies }{ }^{26} \text {. }\end{array}$ & $\begin{array}{l}\text { 15yr follow up EBMT data of } \\
\text { AHSCT in RA }(2012)^{6} \text {. }\end{array}$ & IV Cyc+/-Rituximab. & $\begin{array}{l}\text { Not routine for RA. Optional } \\
\text { for patients with polyarticular } \\
\text { JIA with inadequate response } \\
\text { to steroids + } 2 \text { DMARDs/bio- } \\
\text { logics. }\end{array}$ \\
\hline MS & $\begin{array}{l}\text { One published phase II RCT } \\
\text { (ASTIMS trial) }{ }^{33} \text {. One phase } \\
\text { II RCT awaiting publication } \\
\text { (MIST trial) }^{35} \text {. Multiple single } \\
\text { centre phase II case series. }\end{array}$ & $\begin{array}{l}\text { AHSCT for MS-phase II single- } \\
\text { arm trial (2016) from Canada }{ }^{34} \text {. } \\
24 \text { patients: } 12 \text { RRMS, } 12 \\
\text { SPMS. MS activity-free sur- } \\
\text { vival at } 3 \text { years } 69.6 \% \text {. }\end{array}$ & $\begin{array}{l}\text { Low intensity-IV Cyc+ATG. } \\
\text { Mod intensity-BEAM+ATG. } \\
\text { High intensity-Busulfan, } \\
\text { Cyc+ATG. CD34+ selec- } \\
\text { tion debated. }\end{array}$ & $\begin{array}{l}\text { Recommended for patients } \\
\text { with aggressive/rapidly evolv- } \\
\text { ing or treatment refractory } \\
\text { (disease activity despite high } \\
\text { efficacy biological therapy) } \\
\text { MS in early disease stage. }\end{array}$ \\
\hline $\begin{array}{l}\text { Crohn Dis- } \\
\text { ease }\end{array}$ & Single recent $\mathrm{RCT}(\mathrm{ASTIC})^{42}$. & $\begin{array}{l}\text { AHSCT for refractory Crohn's } \\
\text { disease-a RCT (2015). }\end{array}$ & $\begin{array}{l}\text { IV Cyc } 200 \text { mg/kg+IV ATG } \\
7.5 \mathrm{mg} / \mathrm{kg} \text { (rabbit) +IV } \\
\text { methylprednisolone. }\end{array}$ & $\begin{array}{l}\text { An option for patients with } \\
\text { treatment refractory IBD. Fur- } \\
\text { ther clinical trials will delin- } \\
\text { eate the need for mainte- } \\
\text { nance immunotherapy. }\end{array}$ \\
\hline T1DM & $\begin{array}{l}\text { Three single arm case series } \\
\text { of patients and prospective } \\
\text { phase I / II studies }{ }^{5} \text {. }\end{array}$ & $\begin{array}{l}\text { Updated clinical outcomes of } \\
21 \text { T1DM patients treated with } \\
\text { AHSCT with median follow up } \\
\text { of } 78 \text { months }(2017)^{44} \text {. }\end{array}$ & $\begin{array}{l}\text { IV Cyc } 200 \mathrm{mg} / \mathrm{kg}+\mathrm{IV} \text { ATG } \\
4.5 \mathrm{mg} / \mathrm{kg} \text { (rabbit). }\end{array}$ & $\begin{array}{l}\mathrm{RCTS} \text { are required prior to } \\
\mathrm{AHSCT} \text { being accepted as a } \\
\text { recommended treatment for } \\
\text { T1DM. }\end{array}$ \\
\hline
\end{tabular}

\section{Systemic lupus erythematosus}

Systemic lupus erythematosus (SLE) is a multisystem inflammatory disorder typically affecting the kidney, lung, heart, and/or brain. Historically carrying a poor prognosis, SLE management has improved in the last twenty years because of increased screening, early diagnosis, initiation of immunosuppression, and improved supportive care. Despite this, a proportion of patients fail to respond to pharmacotherapy (typically targeted B cell therapy) and are referred for AHSCT. Whilst no RCT has been performed in this field, large single center studies and the EBMT registry ${ }^{6}$ have confirmed initial treatment responses; however, a relatively large proportion of patients relapse. Data from 53 patients across 23 centers $^{25}$ demonstrate that multiple conditioning regimens from cyclophosphamide, ATG and lymphoid irradiation have been used in AHSCT for SLE. In this analysis, remission of disease activity was seen in 33/50 (66\%; $95 \%$ CI 52-80) evaluable patients by 6 months, of which 10/31
(32\%; 95\% CI 15-50) subsequently relapsed after a median of six (3-40) months. Mortality in numerous studies has been associated with disease duration prior to the transplant ${ }^{6}$. In a study of 28 SLE patients with a median disease duration of 52 months (in which $60 \%$ of patients had lupus nephritis) undergoing AHSCT, a median follow-up of 38 months was achieved. The 5-year overall survival was $81 \%$ and non-relapse mortality was $15 \%$. Five deaths occurred within 2 years after AHSCT, comprising three deaths due to infection, one due to secondary AID, and one due to progressive $\mathrm{SLE}^{26}$.

\section{Rheumatoid arthritis}

Early studies of AHSCT for AID centered around rheumatoid arthritis (RA), the most common inflammatory arthritis, and RA represented the most common early indication for AHSCT in $\mathrm{AID}^{27}$. The procedure was typically well tolerated by the RA patient population, with no TRM reported in early studies ${ }^{28}$ and in general clinical 
response typically lasted up to 2 years, but the majority of patients eventually relapsed ${ }^{4}$. Currently; RA represents only $6.1 \%$ of all cases of RA within the EMBT AID database, and $2.7 \%$ of the CIBMTR database ${ }^{6}$.

\section{Juvenile idiopathic arthritis}

Management of juvenile idiopathic arthritis (JIA) and other inflammatory arthritis including psoriatic and HLA-B27 seronegative arthritis subtypes have again been transformed by the development of biologic agents. JIA now represents $5.6 \%$ of the EBMT AID registry cases ${ }^{6}$. In the EBMT registry, 5-year survival rates are $82 \%$ for JIA post AHSCT; however, the progression-free survival rate was only $52 \%$. Additionally, a retrospective review of 34 patients treated in 9 European centers reported complete response rates of approximately $50 \%{ }^{29}$. Whilst large case series are lacking, individual cases of HSCT for other inflammatory arthritis have been reported, even syngeneic HSCT for a case of severe seronegative RA where clinical improvement was observed over the follow-up period of 24 months $^{30}$. Although sporadic long-term responders do exist, both RA and JIA are likely to become less frequent indications for AHSCT in the future.

\section{Multiple sclerosis and other neuro-inflammatory disorders}

The pivotal report of feasibility of HSCT in MS was published in $1997^{12}$, following a cohort of 15 patients with progressive disease who underwent transplantation from 1995. To date, over 25 Phase I and II clinical trials, and one Phase III clinical trial have been published, expanding our understanding of the role of AHSCT in MS $^{15,19,31-35}$. All reported trials of HSCT in MS have demonstrated a degree of disease stabilization, especially in patients transplanted in the relapsing remitting disease stage. A meta-analysis of 15 studies of 764 MS patients undergoing HSCT reports a disability progression rate of $17.1 \%$ at 2 years and $23.3 \%$ at 5 years in all patients, with a significantly lower progression rate in the RRMS cohort $^{31}$. Other than MS, autologous HSCT has been used in 3 other settings: chronic inflammatory demyelinating polyneuropathy (CIDP) (a chronic inflammatory sensorimotor neuropathy), neuromyelitis optica (NMO), and myasthenia gravis (MG). CDP. Whilst most patients respond to first line immunotherapy, consisting of corticosteroids $+/$ - pooled intravenous immunoglobulin (IVIG), treatment of refractory patients has been considered for AHSCT. Based on positive findings in a series of case reports ${ }^{36-38}$, a Phase II trial of AHSCT for CIDP is currently recruiting ${ }^{5}$. NMO is an inflammatory disorder of the brain and spinal cord in which antibodies against aquaporin- 4 channels the optic nerves and spinal cord. This condition, historically known as Devic's disease, typically associates with a worse prognosis than MS. Although CD-20 monoclonal therapy has proven effective in the majority of difficult-to-manage patients, AHSCT has been considered as a treatment option for NMO. A retrospective analysis of patients $(n=16)$ reported to EBMT reports a relapse-free survival at three years of $31 \%$, which dropped to $10 \%$ at 5 years ${ }^{39}$. Myasthenia gravis is an antibody-mediated disease affecting the acetylcholine receptor of the post-synaptic neuromuscular junction. A small group of treatment-resistant MG patients undergoing AHSCT has been published ${ }^{40}$. All patients had failed several previous lines of therapy including pyridostigmine, steroid therapy, plasma exchange, and IVIG. Median follow-up was 40 months with no treatment-related mortality, and all patients being classified as in complete stable remission at last followup. Again, results from Phase II clinical trials are awaited $^{5}$.

\section{Inflammatory bowel disease}

Crohn's disease (CD) is an inflammatory bowel disease with systemic features, defined by episodic transmural ulceration and inflammation. Approximately $10 \%$ of cases are treatment refractory, and overall, the disease is associated with an increase in all-cause mortality ${ }^{41}$. Until recently, small single arm case series and case reports comprised the bulk of literature surrounding AHSCT for IBD. A 2015 RCT-the 'ASTIC' trial reported early versus delayed (deferred for 1 year) AHSCT in 23 patients ${ }^{42}$. The primary endpoint was clinical disease remission for 3 months, with no medication for $\mathrm{CD}$ and no evidence of active disease on imaging and endoscopy at 1 year. The primary analysis of this trial reported negative results, with no difference between the two treatment groups, and there was one death in the transplant group; however, when the trial was re-analyzed using pooled data and endpoints said to be more 'traditional' for clinical trials of Crohn's disease, it was noted that early HSCT resulted in clinical and endoscopic benefit. At 1 year following HSCT, 3-month steroid-free remission was seen in 13 of 34 patients and complete endoscopic healing in 19 of 38 patients $^{43}$. There was also significant improvement in quality of life measurements. One patient died of transplant-related complications. Long term outcomes on adult patients undergoing AHSCT for IBD continue to be evaluated via the EBMT registry. Future studies using colonoscopic biomarkers may help to delineate the role of HSCT in Crohn's Disease from the expanding number of biologic therapies available to these patients.

\section{Type 1 Diabetes mellitus}

Type 1 diabetes mellitus is an autoimmune disorder marked by $\mathrm{T}$ cell-mediated destruction of $\beta$-cells from pancreatic islets, resulting in diminished and eventual 
complete failure of insulin production. Whilst the majority of patients progress to insulin dependence, theoretical halting of the inflammatory pancreatic destruction may preserve remaining $\beta$ cells and prevent the need for insulin dependence, as can be monitored by stability of C-peptide levels. AHSCT has been trialed for T1DM since the early 2000's. The largest observational study has been recently published by the Sao Paolo group, analyzing long term outcomes in 21 newly diagnosed patients of 25 patients undergoing $\mathrm{AHSCT}^{44}$. Ten patients remained insulin-free for less than 3.5 years post AHSCT, whilst 11 patients remained insulin-free for at least 3.5 years. A further 65 patients, reported in 2 Chinese studies and a single Polish center found that $32 \%$ of patients remained insulin-independent at 48 months ${ }^{5}$. Curiously, outcomes appear to differ in newly diagnosed children, with a case control study of 42 patients showing no advantage to HSCT in newly diagnosed T1DM, which would be inconsistent with the concept of a high functional reserve of $\beta$-cells ${ }^{45}$.

\section{Evolutions in safety}

Based on extensive review of the available literature and expert opinions, the EBMT published recommendations in 2015 on the indications for $\mathrm{AHSCT}^{46}$, and in a similar vein, the America Society for Blood and Marrow Transplantation has established a task force to guide 'routine' indications for HSCT including autoimmune disease ${ }^{47}$. Increasing reassurance surrounding the clinical application of AHSCT has stemmed predominately from improving outcomes in transplant related mortality and morbidity. Over the past two decades, transplant-related mortality has fallen significantly. However, this and other long-term complications surrounding fertility, secondary malignancy, and secondary autoimmune disease ensure AHSCT continues to be reserved for patients with aggressive, treatment refractory disorders.

There is mounting evidence that the improvement in morbidity and mortality rates demonstrated over the past two decades relates to a transplant center's experience. The analytical report of the EBMT registry of patients transplanted between 1996 and $2007^{48}$ supported by those published by Frassoni et al and Loberiza et $\mathrm{al}^{49,50}$, indicates that the numbers of transplants performed per year in a transplant center influences both 100 day transplantrelated mortality and overall survival. Whilst optimal outcomes appear to be associated with centers where AHSCT is performed routinely for AID indications, gaining transplant experience through well-accepted practice of AHSCT and alloHSCT for hematologic indications would undoubtedly enhance staff and center confidence. This may serve as the route of introduction of this therapy for AIDs. Appropriate patient selection through collabo- rations between transplant teams and referring specialists, and clinical monitoring though the peri- and post-transplant period are all essential to shifting the risk-to-benefit ratio of autologous HSCT. From a healthcare policy viewpoint and depending on the needs of individual healthcare regions, the development of specific 'centers of excellence' where experience in clinical care of rare autoimmune diseases undergoing AHSCT is likely to be most cost-effective.

An optimal transplant environment relies not just on the reputation and experience of the center, but training and education of the staff working there. Furthermore, adequate education and training for staff is vital for the development of a functional and safe transplant unit. As outlined in an earlier review by our site ${ }^{51}$, well-trained and educated transplant staff are a precious resource for a transplant center. We recommend a four-pillared model of teaching essential knowledge, enabling practical skills, and encouraging open communication and organizational skills. It is proposed that these keys to professional development when applied to the autologous transplant for AID setting, would further optimize patient outcomes. Centers offering AHSCT for autoimmune diseases should aim to be fully accredited by external, independent accreditation such as the Joint Accreditation CommitteeISCT \& EBMT (JACIE, www.JACIE.org).

Patients with chronic autoimmune diseases require multi-specialty management of their condition. If transplant is selected as the treatment of choice, this should be considered in collaboration with disease-specific specialists to inform on aspects such as patient selection and the impact transplant-related toxicities may have on disease. A 2017 EBMT publication ${ }^{52}$ shows that a chronological improvement has been seen in progression-free survival and non-relapse-related mortality across all indications. When assessing outcomes of first auto-HSCT in a group of 1839 patients with conditions including MS, SSc, IBD, SLE, RA, JIA and T1DM, the 3- and 5-year overall survival rates were $89 \%$ and $86 \%$, with PFS rates of $57 \%$ and $49 \%$ and TRM rates of $4.6 \%$ and $5.3 \%$. Pre-transplantation screening including cardiopulmonary evaluation are of vital importance to exclude patients at high risk of transplant-specific mortality. In patients with refractory autoimmune disease, quality of life is not only affected by the disease but the cumulative morbidity of the disease modifying therapy. A shorter duration therapy such as AHSCT may prove beneficial in a select cohort of AID patients.

\section{Health Economics}

The quest for a single, curative treatment for chronic autoimmune disease remains the goal for patients and health care professionals worldwide. The cornerstone of 
treatment for most AIDs in the developed world today is biological therapies. Whilst efficacious, these are not curative and require long term administration, resulting in long term issues around safety and health economics. As with the development of transplantation in malignancy, AHSCT may be a more acceptable treatment for AID in both developed and developing world as opposed to expensive or access limited biologics.

Examples can be drawn from individual diseases. The annual costs of multiple sclerosis DMT's range from $\$ 50,000-70,000$ USD, noting these are maintenance therapies with undefined durations of treatment, whilst the cost of AHSCT for MS in the USA is roughly $\$ 100,000$ $120,000^{53}$, with AHSCT becoming relatively less expensive after 2-3 years when compared with ongoing disease modifying therapies.

Even excluding complex costs of biologic therapy, autoimmune diseases are costly. T1DM costs in India were estimated to be between $\$ 300-400$ USD per patient in 2002. Using a conservative prevalence estimate of 200, 000 T1DM patients in India at the time, cost of treatment nationally was estimated at $\$ 50$ million, assuming patients were treated in accordance with WHO protocols $^{54}$. A 2008 Brazilian study demonstrated that the cost to families of a family member with rheumatoid arthritis was significantly greater than the average household income ${ }^{55}$. None of these studies incorporated the additional costs of side-effects encountered in patients on chronic immunosuppression. For example, glucocorticoids are associated with adverse effects including weight gain, osteoporosis, avascular necrosis, glaucoma, type 2 diabetes mellitus, cardiovascular disease, and serious infections. Newer therapies, particularly those targeting CD-20 or other B cell markers carry significant risk of infection, most concerningly for countries where these diseases are more prevalent, reactivation of tuberculosis and viral hepatitis, potentially making them inapplicable for use in AID.

Whilst recent EBMT data ${ }^{52}$ correlate rates of activity of AHSCT for AID with the socioeconomic status of a country, it is plausible that, as with acute leukemias, AID may increase as an indication for transplant in the developing world in the coming years. Certainly, from a longterm health economic view point, this may be cost effective-particularly when considering the potential to remain off maintenance immunotherapy and its associated health burden.

\section{Conclusions}

Despite an increase in the development of biological therapies for immune-mediated disease, a proportion of patients with AID remain treatment refractory, resulting in long term morbidity, increased mortality, and eco- nomic burden. Emerging Phase II and III trials and registry data are improving our understanding as to which AIDs are most likely to receive a sustained benefit from AHSCT and which conditioning regimens are preferable. The challenge now is how to initiate transplant services for selected AIDs in a safe and effective manner, especially in the developing world. As outlined earlier-the efficacy of transplant appears to differ significantly between diseases. There are several key factors underpinning this; (1) The benefit of an experienced transplant center, as has been reflected by improved outcomes in numerous studies, along with appropriate center accredi$\operatorname{tation}^{52},(2)$ disease selection, which is key to ensure the risk benefit safety analysis supports AHSCT, as does the cost benefit analysis. Notably, mortality outcomes in MS and IBD appear lower than in SSc and SLE; however, a strong grade of evidence in SSc means that accurately selected patients should still be considered for this option $^{52}$. These disorders currently are the AIDs most likely to benefit globally from AHSCT. However, the need for large, multi-center randomized trials in these diseases still exists to determine superiority when compared with best available pharmacotherapy, or in cases where that has been established, and patient selection and conditioning regimens have been refined.

Ongoing collaborations between hematologists and disease-related specialists, refining the referral pathway, conditioning regimens, and post-transplant care will be key to successful and cost-effective outcomes for patients and society. It is advisable that 'Centers of Excellence' be established in key locations in nations in order to enhance transplant skills and disease familiarity ${ }^{4,52}$ as well as prioritize staffing in resource-limited environments where AID will remain a non-core indication for AHSCT in the future. Ultimately, widespread adoption of AHSCT for AID in the developing world will be a slow process, but nonetheless feasible and potentially cost effective in appropriately selected patients and when performed at the experienced transplantation centers.

\section{Authors' Contribution}

J. C. M. designed, wrote, and edited the manuscript. J. J. M. designed and edited the manuscript. S. M. designed and edited the manuscript. D. D. F. M. designed, wrote, and edited the manuscript.

\section{Conflict of Interest}

J. C. M. has received a post-graduate scholarship from MS Research Australia and has received honoraria from Biogen, Genzyme and Merck. D. D. F. Ma has received research project funding from Phebra Pty Ltd. Disclosure forms provided by the authors are available here. 


\section{References}

1. Cooper GS, Bynum ML, Somers EC. Recent insights in the epidemiology of autoimmune diseases: improved prevalence estimates and understanding of clustering of diseases. J Autoimmun. 2009; 33: 197-207.

2. Bach JF. The effect of infections on susceptibility to autoimmune and allergic diseases. N Engl J Med. 2002; 347: 911-20.

3. Davidson A, Diamond B. Autoimmune diseases. N Engl J Med. 2001; 345: 340-50.

4. Rebeiro P, Moore J. The role of autologous haemopoietic stem cell transplantation in the treatment of autoimmune disorders. Intern Med J. 2016; 46: 17-28.

5. Kelsey PJ, Oliveira MC, Badoglio M, Sharrack B, Farge D, Snowden JA. Haematopoietic stem cell transplantation in autoimmune diseases: From basic science to clinical practice. Current Research in Translational Medicine. 2016; 64: 71-82.

6. Swart JF, Delemarre EM, van Wijk F, Boelens JJ, Kuball J, van Laar JM, et al. Haematopoietic stem cell transplantation for autoimmune diseases. Nat Rev Rheumatol. 2017; 13: 244-56.

7. Congdon CC. Bone marrow transplantation. Science. 1971; 171: $1116-24$.

8. van Gelder M, van Bekkum DW. Treatment of relapsing experimental autoimmune encephalomyelitis in rats with allogeneic bone marrow transplantation from a resistant strain. Bone Marrow Transplant. 1995; 16: 343-51.

9. Snowden JA, Patton WN, O'Donnell JL, Hannah EE, Hart DN. Prolonged remission of longstanding systemic lupus erythematosus after autologous bone marrow transplant for non-Hodgkin’s lymphoma. Bone Marrow Transplant. 1997; 19: 1247-50.

10. Knaan-Shanzer S, Houben P, Kinwel-Bohre EP, van Bekkum DW. Remission induction of adjuvant arthritis in rats by total body irradiation and autologous bone marrow transplantation. Bone Marrow Transplant. 1991; 8: 333-8.

11. van Gelder M, van Bekkum DW. Effective treatment of relapsing experimental autoimmune encephalomyelitis with pseudoautologous bone marrow transplantation. Bone Marrow Transplant. 1996; 18: 1029-34.

12. Fassas A, Anagnostopoulos A, Kazis A, Kapinas K, Sakellari I, Kimiskidis V et al. Peripheral blood stem cell transplantation in the treatment of progressive multiple sclerosis: first results of a pilot study. Bone Marrow Transplant. 1997; 20: 631-8.

13. Snowden JA, Biggs JC, Milliken ST, Fuller A, Brooks PM. A phase I / II dose escalation study of intensified cyclophosphamide and autologous blood stem cell rescue in severe, active rheumatoid arthritis. Arthritis Rheum. 1999; 42: 2286-92.

14. History of the Autoimmune Diseases Working Party, reason for its establishment and its context within the EBMT. In. ebmt. org.

15. Muraro PA, Martin R, Mancardi GL, Nicholas R, Sormani MP, Saccardi R. Autologous haematopoietic stem cell transplantation for treatment of multiple sclerosis. Nat Rev Neurol. 2017; 13: $391-405$.
16. Euler HH, Marmont AM, Bacigalupo A, Fastenrath S, Dreger P, Hoffknecht $\mathrm{M}$ et al. Early recurrence or persistence of autoimmune diseases after unmanipulated autologous stem cell transplantation. Blood. 1996; 88: 3621-25.

17. Moore J, Brooks P, Milliken S, Biggs J, Ma D, Handel M et al. A pilot randomized trial comparing CD34-selected versus unmanipulated hemopoietic stem cell transplantation for severe, refractory rheumatoid arthritis. Arthritis \& Rheumatism. 2002; 46: 2301-9.

18. Curro DV, L. Gualandi, F. Bacigalupo, A. Roccatagliata, L. Capello, E. et al. Low intensity lympho-ablative regimen followed by autologous hematopoietic stem cell transplantation in severe forms of multiple sclerosis: A MRI-based clinical study. Multiple Sclerosis Journal. 2015; 21: 1423-30.

19. Muraro PA, Pasquini M, Atkins HL, Bowen JD, Farge D, Fassas A et al. Long-term Outcomes After Autologous Hematopoietic Stem Cell Transplantation for Multiple Sclerosis. JAMA Neurol. 2017. doi:10.1001/jamaneurol.2016.5867

20. Massey JC, Sutton IJ, Ma DDF, Moore JJ. Regenerating Immunotolerance in Multiple Sclerosis with Autologous Hematopoietic Stem Cell Transplant. Frontiers in Immunology. 2018; 9. doi: 10.3389/fimmu.2018.00410

21. Fransen J, Popa-Diaconu D, Hesselstrand R, Carreira P, Valentini G, Beretta L, et al. Clinical prediction of 5-year survival in systemic sclerosis: validation of a simple prognostic model in EUSTAR centres. Ann Rheum Dis. 2011; 70: 1788-92.

22. Burt RK, Shah SJ, Dill K, Grant T, Gheorghiade M, Schroeder $\mathrm{J}$, et al. Autologous non-myeloablative haemopoietic stem-cell transplantation compared with pulse cyclophosphamide once per month for systemic sclerosis (ASSIST): an open-label, randomised phase 2 trial. Lancet. 2011; 378: 498-506.

23. Sullivan KM, Goldmuntz EA, Keyes-Elstein L, McSweeney PA, Pinckney A, Welch B, et al. Myeloablative Autologous Stem-Cell Transplantation for Severe Scleroderma. N Engl J Med. 2018; 378: 35-47.

24. van Laar JM, Farge D, Sont JK, Naraghi K, Marjanovic Z, Larghero J, et al. Autologous hematopoietic stem cell transplantation vs intravenous pulse cyclophosphamide in diffuse cutaneous systemic sclerosis: a randomized clinical trial. JAMA. 2014; 311: 2490-8.

25. Jayne D, Passweg J, Marmont A, Farge D, Zhao X, Arnold R, et al. Autologous stem cell transplantation for systemic lupus erythematosus. Lupus. 2004; 13: 168-76.

26. Alchi B, Jayne D, Labopin M, Demin A, Sergeevicheva V, Alexander T, et al. Autologous haematopoietic stem cell transplantation for systemic lupus erythematosus: data from the European Group for Blood and Marrow Transplantation registry. Lupus. 2013; 22: 245-53.

27. Tyndall A, Gratwohl A. Blood and marrow stem cell transplants in auto-immune disease: A consensus report written on behalf of the European League against Rheumatism (EULAR) and the European Group for Blood and Marrow Transplantation (EBMT). Bone Marrow Transplant. 1997; 19: 643-5.

28. Snowden JA, Passweg J, Moore JJ, Milliken S, Cannell P, Van 
Laar J, et al. Autologous hemopoietic stem cell transplantation in severe rheumatoid arthritis: a report from the EBMT and ABMTR. J Rheumatol. 2004; 31: 482-8.

29. Brinkman DM, de Kleer IM, ten Cate R, van Rossum MA, Bekkering WP, Fasth A, et al. Autologous stem cell transplantation in children with severe progressive systemic or polyarticular juvenile idiopathic arthritis: long-term follow-up of a prospective clinical trial. Arthritis Rheum. 2007; 56: 2410-21.

30. McColl G, Kohsaka H, Szer J, Wicks I. High-dose chemotherapy and syngeneic hemopoietic stem-cell transplantation for severe, seronegative rheumatoid arthritis. Ann Intern Med. 1999; 131: 507-9.

31. Sormani MP, Muraro PA, Schiavetti I, Signori A, Laroni A, Saccardi R, et al. Autologous hematopoietic stem cell transplantation in multiple sclerosis: A meta-analysis. Neurology. 2017; 88: $2115-22$.

32. Sormani MPM, P. A. Saccardi, R. Mancardi G. NEDA status in highly active MS can be more easily obtained with autologous hematopoietic stem cell transplantation than other drugs. Multiple Sclerosis Journal. 2016 . doi:DOI: $10.1177 /$ 1352458516645670

33. Mancardi GS, M. P. Gualandi, F. Saiz, A. Carreras, E. Merelli, E. et al. Autologous hematopoietic stem cell transplantation in multiple sclerosis A phase II trial. Neurology. 2015; 84: 981-8.

34. Atkins HLB, M. Allan, D. Anstee, G. Arnold, D. A. Bar-Or, A. et al. Immunoablation and autologous haemopoietic stem-cell transplantation for aggressive multiple sclerosis: a multicentre single-group phase 2 trial. Lancet. 2016. doi:http: //dx.doi. org/10.1016/S0140-6736 (16) 30169-6

35. 'Hematopoietic stem cell therapy for patients with inflammatory MS failing alternative approved therapy: a randomized study' . 44th Annual Meeting of the European Society for Blood and Marrow Transplantation; 18.03.2018; Lisbon, Portugal, 2018.

36. Mahdi-Rogers M, Kazmi M, Ferner R, Hughes RA, Renaud S, Steck AJ, et al. Autologous peripheral blood stem cell transplantation for chronic acquired demyelinating neuropathy. J Peripher Nerv Syst. 2009; 14: 118-24.

37. Oyama Y, Sufit R, Loh Y, Statkute L, Yaung K, Quigley K, et al. Nonmyeloablative autologous hematopoietic stem celltransplantation for refractory CIDP. Neurology. 2007; 69: 1802-3.

38. Press R, Askmark H, Svenningsson A, Andersen O, Axelson HW, Stromberg U, et al. Autologous haematopoietic stem cell transplantation: a viable treatment option for CIDP. J Neurol Neurosurg Psychiatry. 2014; 85: 618-24.

39. Greco R, Bondanza A, Oliveira MC, Badoglio M, Burman J, Piehl F, et al. Autologous hematopoietic stem cell transplantation in neuromyelitis optica: a registry study of the EBMT Autoimmune Diseases Working Party. Mult Scler. 2015; 21: 189-97.

40. Bryant A, Atkins H, Pringle CE, Allan D, Anstee G, BenceBruckler I, et al. Myasthenia Gravis Treated With Autologous Hematopoietic Stem Cell Transplantation. JAMA Neurol. 2016; 73: 652-8.
41. Bewtra M, Kaiser LM, TenHave T, Lewis JD. Crohn's disease and ulcerative colitis are associated with elevated standardized mortality ratios: a meta-analysis. Inflamm Bowel Dis 2013; 19: 599-613.

42. Hawkey CJ, Allez M, Clark MM, Labopin M, Lindsay JO, Ricart E, et al. Autologous Hematopoetic Stem Cell Transplantation for Refractory Crohn Disease: A Randomized Clinical Trial. JAMA. 2015; 314: 2524-34.

43. Lindsay JO, Allez M, Clark M, Labopin M, Ricart E, Rogler G, et al. Autologous stem-cell transplantation in treatment-refractory Crohn's disease: an analysis of pooled data from the ASTIC trial. Lancet. Gastroenterol Hepatol. 2017; 2: 399-406.

44. Malmegrim KC, de Azevedo JT, Arruda LC, Abreu JR, Couri $\mathrm{CE}$, de Oliveira GL, et al. Immunological Balance Is Associated with Clinical Outcome after Autologous Hematopoietic Stem Cell Transplantation in Type 1 Diabetes. Front Immunol. 2017; 8: 167.

45. Gu Y, Gong C, Peng X, Wei L, Su C, Qin M, et al. Autologous hematopoietic stem cell transplantation and conventional insulin therapy in the treatment of children with newly diagnosed type 1 diabetes: long term follow-up. Chin Med J (Engl) 2014; 127: 2618-22.

46. Sureda A, Bader P, Cesaro S, Dreger P, Duarte RF, Dufour C, et al. Indications for allo- and auto-SCT for haematological diseases, solid tumours and immune disorders: current practice in Europe, 2015. Bone Marrow Transplant. 2015; 50: 1037-56.

47. Majhail NS, Farnia SH, Carpenter PA, Champlin RE, Crawford S, Marks DI, et al. Indications for Autologous and Allogeneic Hematopoietic Cell Transplantation: Guidelines from the American Society for Blood and Marrow Transplantation. Biol Blood Marrow Transplant. 2015; 21: 1863-69

48. Farge D, Labopin M, Tyndall A, Fassas A, Mancardi GL, Van Laar J, et al. Autologous hematopoietic stem cell transplantation for autoimmune diseases: an observational study on 12 years' experience from the European Group for Blood and Marrow Transplantation Working Party on Autoimmune Diseases. Haematologica. 2010; 95: 284-92.

49. Frassoni F, Labopin M, Powles R, Mary JY, Arcese W, Bacigalupo A, et al. Effect of centre on outcome of bone-marrow transplantation for acute myeloid leukaemia. Acute Leukaemia Working Party of the European Group for Blood and Marrow Transplantation. Lancet. 2000; 355: 1393-8.

50. Loberiza FR, Jr., Zhang MJ, Lee SJ, Klein JP, LeMaistre CF, Serna DS, et al. Association of transplant center and physician factors on mortality after hematopoietic stem cell transplantation in the United States. Blood. 2005; 105: 2979-87.

51. Ma DDF. HSCT Center's Success is Dependent upon Adequate Staff Education and Training. In: Gluckman É, Niederwieser D, Aljurf M (eds). Establishing a Hematopoietic Stem Cell Transplantation Unit: A Practical Guide. Springer International Publishing: Cham, 2018, pp271-279.

52. Snowden JA, Badoglio M, Labopin M, Giebel S, McGrath E, Marjanovic Z, et al. Evolution, trends, outcomes, and economics of hematopoietic stem cell transplantation in severe autoim- 
mune diseases. Blood Adv. 2017; 1: 2742-55.

53. Scolding NJ, Pasquini M, Reingold SC, Cohen JA, International Conference on Cell-Based Therapies for Multiple S, International Conference on Cell-Based Therapies for Multiple S et al. Cell-based therapeutic strategies for multiple sclerosis. Brain. 2017; 140: 2776-96

54. Shobhana R, Rama Rao P, Lavanya A, Williams R, Padma C, Vijay V, et al. Costs incurred by families having Type 1 diabe- tes in a developing country--a study from Southern India. Diabetes Res Clin Pract. 2002; 55: 45-8.

55. Chermont GC, Kowalski SC, Ciconelli RM, Ferraz MB. Resource utilization and the cost of rheumatoid arthritis in Brazil. Clin Exp Rheumatol. 2008; 26: 24-31.

https://doi.org/10.31547/bct-2018-009

Copyright (C) 2018 APBMT. All Rights Reserved. 